\title{
Improvement of adhesion performance between aluminum alloy sheet and epoxy based on anodizing technique
}

\author{
Yiwei $\mathrm{Xu}^{1}$, Huaguan $\mathrm{Li}^{1}$, Yizhou Shen ${ }^{1}$, Senyun $\mathrm{Liu}^{2}$, Wentao Wang ${ }^{1}, \mathrm{Jie}^{\mathrm{Ta}}{ }^{1 *}$ \\ ${ }^{1}$ College of Material Science \& Technology, Nanjing University of Aeronautics and Astronautics,
} Nanjing 211100, P.R. China

${ }^{2}$ College of Aerospace Engineering, Nanjing University of Aeronautics and Astronautics, Nanjing 211100, P.R. China

Abstract: The infiltration behavior of epoxy on the surface of the aluminum alloy sheets with different roughness and surface energy was studied to enhance adhesion performance. In this study, the aluminum alloy sheets were treated with the process of phosphoric acid anodizing (PAA) under different parameters. The as-formed uniform pits and nanometer-scale pores contributed to the change of apparent surface energy and surface roughness. Then the morphologies of the interface between epoxy and the aluminum alloy sheet were observed by SEM. The adhesion strength was characterized by the lap-shear tensile test. The results indicated that the modes of epoxy wetting had mainly two types. Apparent surface energy played a leading role in improving adhesive bonding at the state of fully wetting, while the value of roughness could affect adhesion strength greatly at the state of incompletely wetting. The specimen exhibited the ultimate interfacial adhesion strength of 52.45 $\mathrm{MPa}$ and optimal hygrothermal ageing resistance

"Corresponding author. Tel/Fax.:+86 02552112911

E-mail address: taojie@nuaa.edu.cn (J.Tao) 
when the apparent surface energy value was $84.62 \mathrm{~mJ} / \mathrm{m}^{2}$ and the roughness value was $0.720 \mu \mathrm{m}$.

Keywords: Aluminum and alloys, Anodizing, Apparent surface energy, Surface roughness, Adhesion

\section{Introduction}

Fiber metal laminates (FMLs) are hybrid materials based on alternating layers of thin metal sheets and fiber reinforced composite plies. The hybrid materials combine the advantages of metallic materials and fiber reinforced matrix systems [1-3]. As the second generation of FMLs, GLARE is manufactured by unidirectional glass fiber reinforced prepregs and 2024 aluminum alloy sheets, which processes high strengths, excellent fatigue and impact resistance [4,5]. However, the development of advanced composites request more excellent damage tolerance of FMLs. Recent years, kinds of novel aluminum alloy, especially the aluminum-lithium alloy, exhibit more excellent damage tolerance than the conventional 2024 aluminum alloy. The attractive performance of aluminum-lithium alloy, including lower density, better strength and higher stiffness, facilitates its wide applications in the aerospace industry.

We have already proved that the novel fiber metal laminates (NFMLs) based on aluminum-lithium alloy have higher modulus and damage tolerance [6]. However, the adhesion between the fiber-epoxy composite lamina and the treated novel aluminum alloy sheet is a key issue which restricts further application of NFMLs [7,8]. Technique of adhesive bonding was introduced by the aircraft industry in England in the 1940s. Adams et al. [9] have published a concise guide to adhesive joints within structures. The 
book analyses surface preparation by physical or chemical methods. Experiences demonstrated that the surface treatment prior to bonding was the most critical step which could not be disregarded, since it was essential to achieve long-term service capability [10-12].

People have been trying to enhance the adhesion. Recently, carbon nanotube (CNT)-reinforced epoxy has been developed as an adhesive owing to its high adhesion strength and good durability [13]. It has been testified that the increase of interfacial property attributes to the decreased contact angle, improved surface roughness and increased fiber surface area of the CNT-grafted fibers [14,15] and mechanical interlock between CNTs and the matrix. Nevertheless, the new epoxy cannot be widely used due to its high cost. Besides, chemical bonding can also be introduced as a dominant adhesion strength enhancement factor by embedding a coupling agent at the interface and forming a metal/coupling agent/polymer system [16] or modifying the metal surface [17]. However, the application of these techniques is impractical nowadays because of the low reliability and stability of these methods. Studies showed that good adhesion between aluminum alloys and adhesives could be obtained when the alloys were degreased in alkaline solutions or organic solvents and subsequently etched in acid solutions. However, it was found that the surface pre-treatment was insufficient in certain non-bonded areas where corrosion occurred. The corrosion susceptibility was reduced if the aluminum surface, after acid etching, was anodized before bonding [18]. Hence good adhesion property could be acquired through anodizing with the advantages of low cost and high stability [19]. Rahimi et al. [20] and Stępniowski et al. [21] have demonstrated that 
nanostructure can be produced by PAA and is affected by the time of pretreatment and anodizing parameters. Moreover, the effects of hole diameter and depth on the wetting behavior of porous anodic alumina have been discussed [22,23]. Nevertheless, the wetting behavior of epoxy remains to be seen because it is different from that of water.

The good wettability of epoxy is generally considered to be beneficial to the adhesion of the fiber-epoxy composite laminas and the aluminum alloy sheets [24]. Ordinarily, the wettability of liquid can be obtained by measuring the contact angle of liquid on the surface of the aluminum alloy sheet. However, the contact angle of epoxy is difficult to measure because epoxy has the characteristics of high viscosity and poor mobility. Therefore it is difficult for epoxy to infiltrate into the porous structure on the aluminum alloy sheet without pressure. In the present work, the aluminum alloy sheets were treated by PAA of different parameters to obtain different surface energy and roughness. Specimens of the sort normally used for the lap-shear tensile test were applied to observation of the interface between epoxy and the aluminum alloy sheet. The infiltration behaviors of epoxy on the surface of the aluminum alloy sheets and the effect of mechanical interlocking between epoxy and the aluminum alloy sheets were studied to investigate the influence of surface energy and roughness on adhesive bonding. Consequently, the interfacial adhesion strength could be improved by adjusting the value of surface energy and roughness. This study could provide a powerful support for the evaluation of adhesive bonding property via apparent surface energy and roughness of the aluminum alloy sheets.

\section{Experimental}




\subsection{Materials}

The 2060-T8 aluminum alloy sheets with a thickness of $2 \mathrm{~mm}$ were selected in this study. The novel aluminum alloy consisted of $0.7 \mathrm{wt} \%$ lithium, $3.7 \mathrm{wt} \%$ copper, $0.7 \mathrm{wt} \%$ magnesium, $0.34 \mathrm{wt} \%$ silver, $0.11 \mathrm{wt} \%$ zirconium, $0.29 \mathrm{wt} \%$ manganese, $0.32 \mathrm{wt} \%$ zinc and aluminum. For surface treatment samples $20 \mathrm{~mm} \times 20 \mathrm{~mm}$ in size were prepared. The No.J116 adhesive film (supplied by Institute of Petrochemistry Heilongjiang Academy of Sciences) was applied to the lap-shear tensile test.

\subsection{Surface treatment}

Solvent degreasing is an effective way to remove the contaminant materials which inhibit the formation of the chemical bonds, but it makes no contribution to the formation of acceptable surface conditions for longer term bond durability, although providing a clean surface. Even so, all aluminum alloy sheets are supposed to be degreased before further surface pretreatment.

Generally, the aluminum alloy sheets should be pre-treated to remove the natural alumina film prior to anodizing. Alkaline solution dissolves the oxide film and nitric acid solution corrodes the alloy itself followed. Alkaline cleaning for the specimens was performed in the solution of 25-30 g/l NaOH and 25-30 g/ $\mathrm{Na}_{2} \mathrm{CO}_{3}$ at 50-60 ${ }^{\circ} \mathrm{C}$ for $0.5-1$ min. Subsequently, the specimens were immersed in $400 \mathrm{~g} / \mathrm{l}$ nitric aqueous solution for 2-5 min at room temperature. After each step, the specimens were rinsed with distilled water and dried in the air [25].

Boeing developed the PAA, which led to a clearly better joint durability [7]. PAA was conducted in the phosphoric acid solution with a constant voltage. The anodizing 
experiments were operated with a programmable D.C power supply (WYK-1502, Yangzhou Aikesai Electronic Co., Ltd., China). Aluminum alloys are traditionally treated in the solution of 9-12 wt \% phosphoric acid solution at $19-25{ }^{\circ} \mathrm{C}$ for $20-25$ min with a voltage 9-11 V in aerospace industry, in accordance with BAC 5555 of Boeing Company. This PAA method has been applied to 2024 aluminum alloy in the fabrication of GLARE laminates. The adhesion strength of the interface between treated 2024 aluminum alloy sheets and epoxy can reach about $45 \mathrm{MPa}$ and meets the requirement of aerospace industry basically. However, the anodizing parameters of the novel aluminum alloy may be different owing to the great distinction of chemical composition. The effects of experiment parameters such as electrolyte concentration, voltage, temperature and time on contact angles were systemically studied in the prophase work. Five processes (Table 1) with representative water contact angles ranging from $0^{\circ}$ to $50^{\circ}$ were chosen in this work. After anodizing, the specimens were rinsed thoroughly with distilled water for at least 5 mins and dried in the desiccator at $60{ }^{\circ} \mathrm{C}$ for 15 mins. The significant advantage of the surface treatment used in this work is the absence of $\mathrm{Cr}$ (VI). Alkaline cleaning and PAA were adopted because the effect of dichromate-sulfuric acid etching was considered to be unstable by Boeing Company and $\mathrm{Cr}$ (VI) had serious environmental pollution.

\subsection{Surface analysis}

The contact angles of water and glycol droplets on the aluminum alloy sheets were measured by the JC2000D7M contact angle analyzer. The surfaces produced by the PAA were hydrophilic. The surfaces with different water contact angles had different apparent surface energy. Therefore, five samples with representative water contact angles ranging 
from $0^{\circ}$ to $50^{\circ}$ were chosen to observe the surface morphologies by FEI Quanta 200 scanning electron microscope. Then the roughness values $\mathrm{Ra}$ of the samples were evaluated by a rugosimeter. Ra is the arithmetical average value of the departure of the profile above and below the mean line throughout the specified sampling length. The sampling length of surface selected in this evaluation was 8mm according to BS 1134 . Moreover, the surface morphologies of the interface between epoxy and the aluminum alloy sheets of the test specimens were observed by FEI Quanta 200 scanning electron microscope.

\subsection{Lap-shear tensile test and durability test}

The form and dimensions of test specimens are shown in Fig. 1 according to ASTM D1002. The lap-shear tensile tests of PAA-treated aluminum alloy samples were conducted by CMT-5105 universal electronic testing machine (Fig. 2). Moreover, the lap-shear tensile tests were used to determine the durability of the adhesively bond joints. Durability represents one of the greatest challenges in the design of structures in general and in composite structures in particular. Specimens were exposed to $95 \%$ relative humidity and $70{ }^{\circ} \mathrm{C}$ temperature environment for 200,400 and 600 hours respectively. The adhesion strength obtained by the lap-shear tensile test reflected the adhesion property of joints fabricated with PAA-treated aluminum alloy sheets effectively.

\section{Results and discussion}

\subsection{Surface morphologies}

The surface morphology of the pre-treated aluminum alloy sheet is shown in Fig. 3. Obviously, some uneven pits are formed on the sheet surface owing to the corrosion 
effect of nitric acid electrolyte. The existence of pits can improve adhesion strength to some degree by increasing the bonding area.

A dense oxide film is formed on the aluminum alloy sheet surface during the electrochemical reaction of anodizing. The growth of the porous oxide consists of several stages. When an anodic voltage is applied, a barrier layer of alumina is formed on the surface of the aluminum alloy sheet. Then tiny cracks appear at the oxide/electrolyte interface and widen to pores. The process involves oxide film growth and dissolution driven by an external electric field and can be expressed as follows $[19,26]$ :

$$
\begin{aligned}
& \text { Growth: } 2 \mathrm{Al}+3 \mathrm{H}_{2} \mathrm{O} \rightarrow \mathrm{Al}_{2} \mathrm{O}_{3}+6 \mathrm{H}^{+}+6 \mathrm{e}^{-} \\
& \text {Dissolution: } \mathrm{Al}_{2} \mathrm{O}_{3}+6 \mathrm{H}^{+} \rightarrow 2 \mathrm{Al}^{3+}+3 \mathrm{H}_{2} \mathrm{O}
\end{aligned}
$$

The reaction is able to attain a constant dissolution speed and reach a balance state. Such a well-developed pore structure consists of closely packed hexagonal cells with a central pore perpendicular to the metal surface and the thin compact barrier oxide layer.

Anodizing is conducted on the basis of pretreatment. The thickness of the anodized film is approximately $550 \mathrm{~nm}$. The surface morphologies of five samples are depicted in Fig. 4. It is obvious that some uniform pits and nanometer-scale pores are formed on the PAA-treated aluminum alloy sheets. Epoxy is able to penetrate into the uniform pits with size of a few microns during the process of infiltration. The mechanical interlocking effect between epoxy and the substrate after curing is beneficial to the improvement of adhesion. Meanwhile, the sizes of the nanometer-scale pores are about several tens of nanometers in diameter and vary by the anodizing parameters. The size of the pore has great influence on apparent surface energy (i.e. the surface with smaller pore size owns 
higher apparent surface energy [27]). Hence the structure of the pore can affect the infiltration behavior and the wetting state of epoxy on the sheets surface, leading to the change of adhesion property.

\subsection{Apparent surface energy and roughness of sheets}

The hydrophilic surface with lower water contact angle has higher apparent surface energy [28]. Figure 5 shows the photographs of $4 \mu \mathrm{l}$ water droplets on the anodized aluminum alloy sheets. The water contact angle gradually increases from $0^{\circ}$ to $50^{\circ}$ as a result of the reduction of apparent surface energy. Similarly the contact angles of $4 \mu \mathrm{l}$ glycol droplets on the anodized sheets with different apparent surface energy were measured. The results are listed in Table 2.

The adhesion of liquids on the solid surface can be described by the work of $\operatorname{adhesion}\left(W_{a}\right)$.

$$
W_{a}=\gamma_{S V}+\gamma_{L V}-\gamma_{S L}
$$

Then Young's equation (eq. 2) is used to get equation 3.

$$
\begin{gathered}
\gamma_{S V}=\gamma_{S L}+\gamma_{L V} \cos \theta \\
W_{a}=\gamma_{L V}(1+\cos \theta)
\end{gathered}
$$

The work of adhesion includes the polar component and the dispersion component (eq. 4). Therefore apparent surface energy is calculated according to the equation 5 and 6 as follows:

$$
\begin{gathered}
W_{a}=2 \sqrt{\gamma_{S V}^{d} \gamma_{L V}^{d}}+2 \sqrt{\gamma_{S V}^{p} \gamma_{L V}^{p}} \\
r_{L V}(1+\cos \theta)=2 \sqrt{r_{S V}^{d} r_{L V}^{d}}+2 \sqrt{r_{S V}^{p} r_{L V}^{p}} \\
\gamma_{S V}=\gamma_{S V}^{p}+\gamma_{S V}^{d}
\end{gathered}
$$


where $\gamma_{S V}^{p}$ and $\gamma_{L V}^{p}$ are the polar components of the solid surface energy and the liquid surface energy, while $\gamma_{S V}^{d}$ and $\gamma_{L V}^{d}$ are the dispersion components of the solid surface energy and the liquid surface energy respectively. Water and glycol are employed as probe liquids whose surface tension components are known (Table 3). The component of the sheet surface can be determined by measuring the contact angle $\theta$.

The calculated apparent surface energy and measured roughness values are presented in Table 2. The data reveal that the value of apparent surface energy decreases and that of roughness increases with the increase of water contact angle. Generally speaking, the sheet surface with higher apparent surface energy shows better water wettability. However, the infiltration behavior of epoxy is different from that of water. Thus high apparent surface energy is not always beneficial to the wetting of epoxy on the sheet surface. Moreover, the increased roughness can increase the bonding area, it does not mean that it is always good for adhesive bonding because of the distinct effect of roughness on fully wetted surface and incomplete wetted surface.

\subsection{The infiltration of epoxy}

Morphologies of the interface between epoxy and the anodized aluminum alloy sheet are shown in Fig. 6. It is obviously seen that the infiltration of epoxy on porous alumina surface has two different modes. The infiltration of epoxy follows the mode 1 for samples 3, 4 and 5, while the infiltration of epoxy follows the mode 2 for samples 1 and 2. Uniform pits and nanometer-scale pores are formed on the sheets during anodizing. Epoxy can easily infiltrate into the pits, yet it cannot always infiltrate into the nanometer-scale pores because the size of the pores can affect the wetting behavior. 
A mechanism based on the capillary wetting of the pore is applied to explain the observed infiltration process of epoxy. The capillary force is regarded as the driving force for epoxy to penetrate into the hole [22]. The capillary wetting of the pore surface can be controlled by two critical factors: the ratio of the pore diameter to the pore spacing, and the ratio of the pore depth to the pore diameter. Hence the capillary wetting mechanism changes with the microstructure. Epoxy not only infiltrates into the pits but also penetrates into the nanometer-scale pores under the capillary force for samples 3, 4 and 5 (Fig. 6(a)). Nevertheless, it is evident that epoxy cannot infiltrates into the nanometer-scale pores for samples 1 and 2 . The gases exist in the pores and prevent epoxy from further penetrating in the form of mode 2 (Fig. 6(b)) $[22,26]$.

\subsection{Adhesion property}

The values of adhesion strength are presented in Fig. 7. Apparent surface energy can greatly influence adhesion property [29]. It is found that the adhesion strength does not keep increasing with the increase of apparent surface energy. The adhesion strength of the specimen with the apparent surface energy value of $84.62 \mathrm{~mJ} / \mathrm{m}^{2}$ is the highest. The results suggest that the sample whose apparent surface energy is approximately 84.62 $\mathrm{mJ} / \mathrm{m}^{2}$ exhibits the optimal adhesion performance of $52.45 \mathrm{MPa}$, which is superior to that required in aerospace industry.

The infiltration of epoxy follows the mode 1 (Fig. 6(a)) when the value of apparent surface energy is relatively low. Epoxy penetrates into the uniform pits as well as the nanometer-scale pores. It means that the sheet is fully wetted. As a consequence, a strong bond between epoxy and the substrate can be formed during the process of epoxy curing. 
The adhesion strength is greatly improved due to the mechanical interlocking effect. It is noticed that the interfacial energy increases with the apparent surface energy increasing. The high interface energy is benefit to the infiltration of epoxy for samples that can be fully wetted. Therefore the adhesion strength keeps increasing with the increase of apparent surface energy at this wetting state. When the value of apparent surface energy exceeds a certain range, the infiltration of epoxy follows the mode 2. Epoxy cannot penetrate into the nanometer-scale pores. Thus the mechanical interlocking effect between epoxy and the substrate is weakened, leading to a sharp decline of adhesion performance.

The variation of roughness is different from that of apparent surface energy. The values of adhesion strength of samples with different roughness are given in Fig. 8. The data indicate that the sample with the roughness value of about $0.720 \mu \mathrm{m}$ possesses the optimal adhesion property. The infiltration of epoxy follows the mode 2 when the roughness value is relatively low. The adhesion strength is found to increase with the increase of surface roughness under the condition of mode 2 , because the increased roughness promotes the enhancement of the mechanical interlocking effect by expanding the adhesion area. However, the increased roughness does not have the same effect when the infiltration of epoxy follows the mode 1.

It is generally considered that one important limitation of adhesive bonding is the lack of confidence in the long-term behavior under conditions of high humidity and temperature. The durability experimental results of aluminum alloy joints bonded with epoxy are given in Fig. 9. It can be seen that strength loss of specimen presents with the 
prolongation of ageing time, but varies by surface treatment process. The strength reduction of specimens treated by the last three processes is relatively slow. Nevertheless, the specimens fabricated through process 1 and 2 lost their strength nearly 9\% after 600 hours. Consequently, the durability of samples treated by process 3 is the optimal, while that of samples treated by process 1 and 2 is the worst. This may be caused by the microstructure of aluminum alloy surface. The conditions of mode 2 that epoxy penetrate into the uniform pits only make it easy for water to infiltrate into the unfilled pores in humid environment. Hence, the damage of adhesive bonding is aggravated under this circumstance.

\section{Conclusions}

(1) The infiltration of epoxy on porous alumina surface had two modes, fully wetting and incompletely wetting. Fully wetting meant that epoxy could infiltrate into both the uniform pits and the nanometer-scale pores during the process of infiltration, and the state that epoxy could only penetrate into the uniform pits was incompletely wetting.

(2) The increase of apparent surface energy promoted the enhancement of the mechanical interlocking effect at the state of fully wetting, resulting in the improvement of adhesion property. The increased roughness was beneficial to adhesive bonding as a result of the expansion of the bonding area when the surface was incompletely wetted.

(3) The adhesion performance between aluminum alloy sheet and epoxy of fiber metal laminates could be improved based on anodizing technique. The specimen with the 
apparent surface energy value of $84.62 \mathrm{~mJ} / \mathrm{m}^{2}$ and the roughness value of $0.720 \mu \mathrm{m}$ had the ultimate interfacial adhesion strength of $52.45 \mathrm{MPa}$ and the optimal durability.

\section{Acknowledgments}

The authors gratefully acknowledge the financial support of the Fund of National Engineering and Research Center for Commercial Aircraft Manufacturing (No: SAMC 13-JS-15-032), Jiangsu Innovation Program for Graduate Education (KYLX_0259), Opening Project of Jiangsu Key Laboratory of Advanced Structural Materials and Application Technology (ASMA201401), the National Science Foundation of China (No.11372335) and Project Funded by the Priority Academic Program Development of Jiangsu Higher Education Institutions.

\section{References}

[1] Vlot A, Gunnink JW. Fibre metal laminates: an introduction. Berlin: Springer; 2001.

[2] Fu Y, Zhong J, Chen Y. Thermal postbuckling analysis of fiber-metal laminated plates including interfacial damage. Compos Part B-Eng 2014;56(1):358-364.

[3] Lee BE, Park ET, Kim J, Kang BS, Song WJ. Analytical evaluation on uniaxial tensile deformation behavior of fiber metal laminate based on SRPP and its experimental confirmation. Compos Part B-Eng 2014;67(67):154-159.

[4] Vlot A. Glare: history of the development of a new aircraft material. Berlin: Springer Science and Business Media; 2001.

[5] Moriniere FD, Alderliesten RC, Benedictus R. Low-velocity impact energy partition 
in GLARE. Mech Mater 2013;66:59-68.

[6] Li HG, Ling J, Xu YW. Effect of aging treatment on precipitation behavior and mechanical properties of a novel aluminum-lithium alloy. Acta Metall Sin 2015;28(6):671-677.

[7] Sinmazçelik T, Avcu E, Bora MÖ, Coban O. A review: fibre metal laminates, background, bonding types and applied test methods. Mater Design 2011;32(7):3671-3685.

[8] Golru SS, Attar MM, Ramezanzadeh B. Effects of surface treatment of aluminium alloy 1050 on the adhesion and anticorrosion properties of the epoxy coating. Appl Surf Sci 2015;345:360-368.

[9] Adams RD, Wake WC. Structural Adhesive Joints in Engineering. London: Elsevier Applied Science Publishers; 1997.

[10]Ho BJ, Tsoi JKH, Liu D, Lung CYK, Wong HM, Matinlinna JP. Effects of sandblasting distance and angles on resin cement bonding to zirconia and titanium. Int J Adhes Adhes 2015;62:25-31.

[11] Shi J, Pries H, Stammen E, Dilger K. Chemical pretreatment and adhesive bonding properties of high-pressure die cast aluminum alloy: AlSi10MnMg. Int J Adhes Adhes 2015;61:112-121.

[12]Zheng R, Lin J, Wang PC. Effect of adhesive characteristics on static strength of adhesive-bonded aluminum alloys. Int J Adhes Adhes 2015;57:85-94.

[13] Yu S, Tong MN, Critchlow G. Use of carbon nanotubes reinforced epoxy as adhesives to join aluminum plates. Mater Design 2010;31:126-129. 
[14] Wang C, Li Y, Tong L. The role of grafting force and surface wettability in interfacial enhancement of carbon nanotube/carbon fiber hierarchical composites. Carbon 2014;69:239-246.

[15] Islam MS, Deng Y, Tong LY. Grafting carbon nanotubes directly onto carbon fibers for superior mechanical stability: towards next generation aerospace composites and energy storage applications. Carbon 2016;96:701-710.

[16] Samia MC, Sarra GD, Claire M, Mohamed MC. Aryl diazonium salts: a new class of coupling agents for bonding polymers, biomacromolecules and nanoparticles to surfaces. Chem Soc Rev 2011;40(7):4143-4166.

[17]Basak GC, Bandyopadhyay A, Neogi S, Bhowmick AK. Surface modification of argon/oxygen plasma treated vulcanized ethylene propylene diene polymethylene surfaces for improved adhesion with natural rubber. Appl Surf Sci 2011;257(7):2891-2904.

[18] Sheasby PG, Pinner R. The surface treatment and finishing of aluminum and its alloys. 6th ed. UK: Finishing Publications Ltd; 2001.

[19] Wang SB, Zhai B, Zhang BM. The effect of the microstructure of porous alumina films on the mechanical properties of glass-fiber-reinforced aluminum laminates. Compos Interface 2014;21(5):381-393.

[20] Rahimi MH, Saramad S, Tabaian SH. Study the effect of striping in two-step anodizing process on pore arrangement of nano-porous alumina. Appl Surf Sci 2009;256(1):12-16.

[21] Stępniowski WJ, Bojar Z. Synthesis of anodic aluminum oxide (AAO) at relatively 
high temperatures. Study of the influence of anodization conditions on the alumina structural features. Surf Coat Tech 2011;206(2):265-272.

[22]Ran CB, Ding GQ, Liu WC, Deng Y, Hou WT. Wetting on nanoporous alumina surface: transition between Wenzel and Cassie states controlled by surface structure. Langmuir 2008;24(18):9952-9955.

[23]Lee W, Park SJ. Porous anodic aluminum oxide: anodization and templated synthesis of functional nanostructures. Chem Rev 2014;114(15):7487-7556.

[24]Botelho EC, Silva RA. Evaluation of adhesion of continuous fiber-epoxy composite/aluminum laminates. J Adhes Sci Technol 2004;18(15-16):1799-1813.

[25] Sun ZQ, Huang MH, Hu GH. Surface treatment of new type aluminum lithium alloy and fatigue crack behaviors of this alloy plate bonded with Ti-6Al-4V alloy strap. Mater Design 2012;35:725-730.

[26] Vrublevsky I, Parkoun V, Schreckenbach J. Analysis of porous oxide film growth on aluminum in phosphoric acid using re-anodizing technique. Appl Surf Sci 2005;242(3):333-338.

[27]Lee W. Nanoporous alumina. Berlin: Springer; 2015.

[28] Subedi DP. Contact angle measurement for the surface characterization of solids. Himalayan Phys 2011;2(2):1-4.

[29] Islam MS, Tong L, Falzon PJ. Influence of metal surface preparation on its surface profile, contact angle, surface energy and adhesion with glass fibre prepreg. Int $\mathrm{J}$ Adhes Adhes 2014;51(6):32-41. 


\section{Figures}

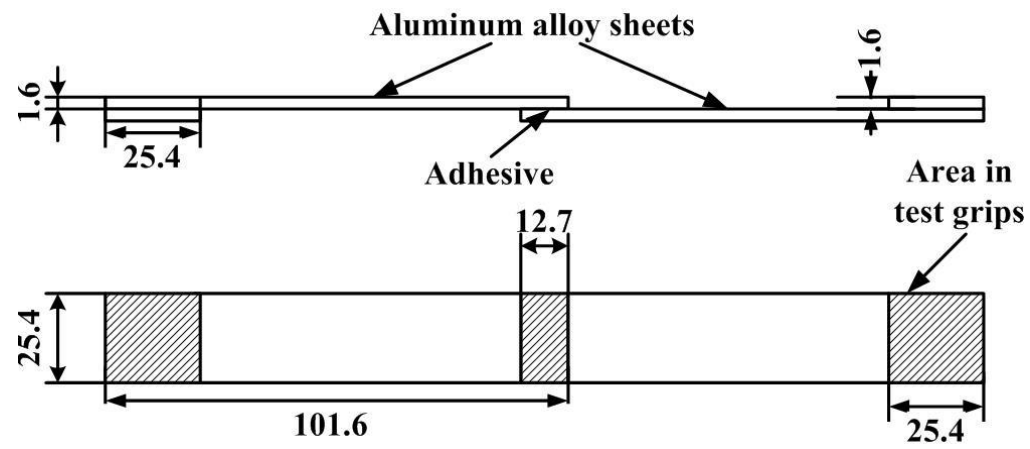

Fig. 1. The form and dimensions of test specimens.

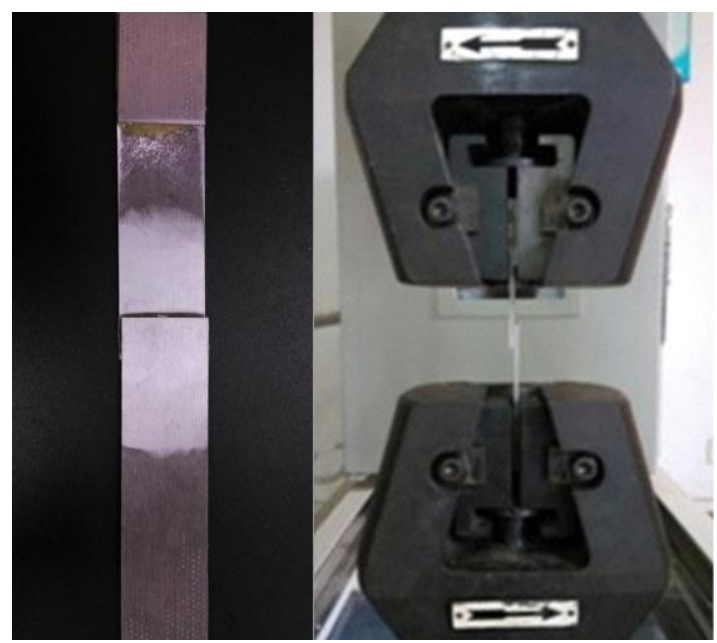

Fig. 2. The CMT-5105 universal electronic testing machine.

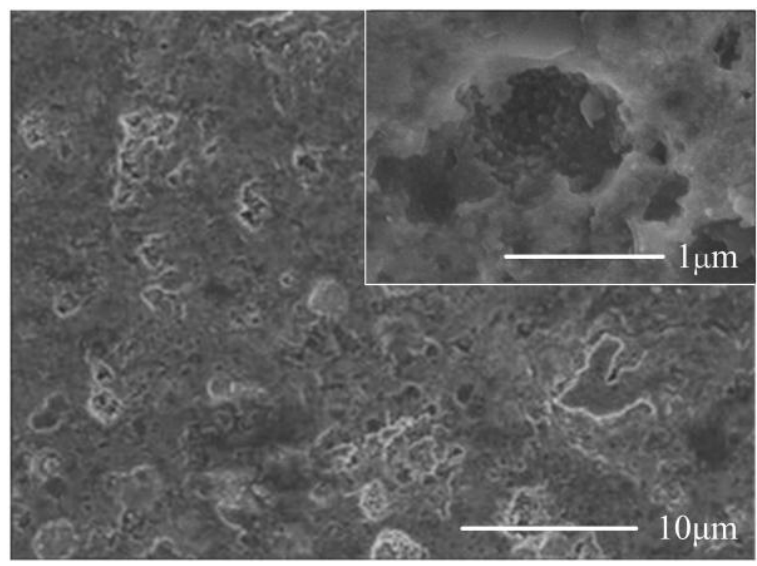

Fig. 3. The surface morphology of the pre-treated aluminum alloy sheet. 


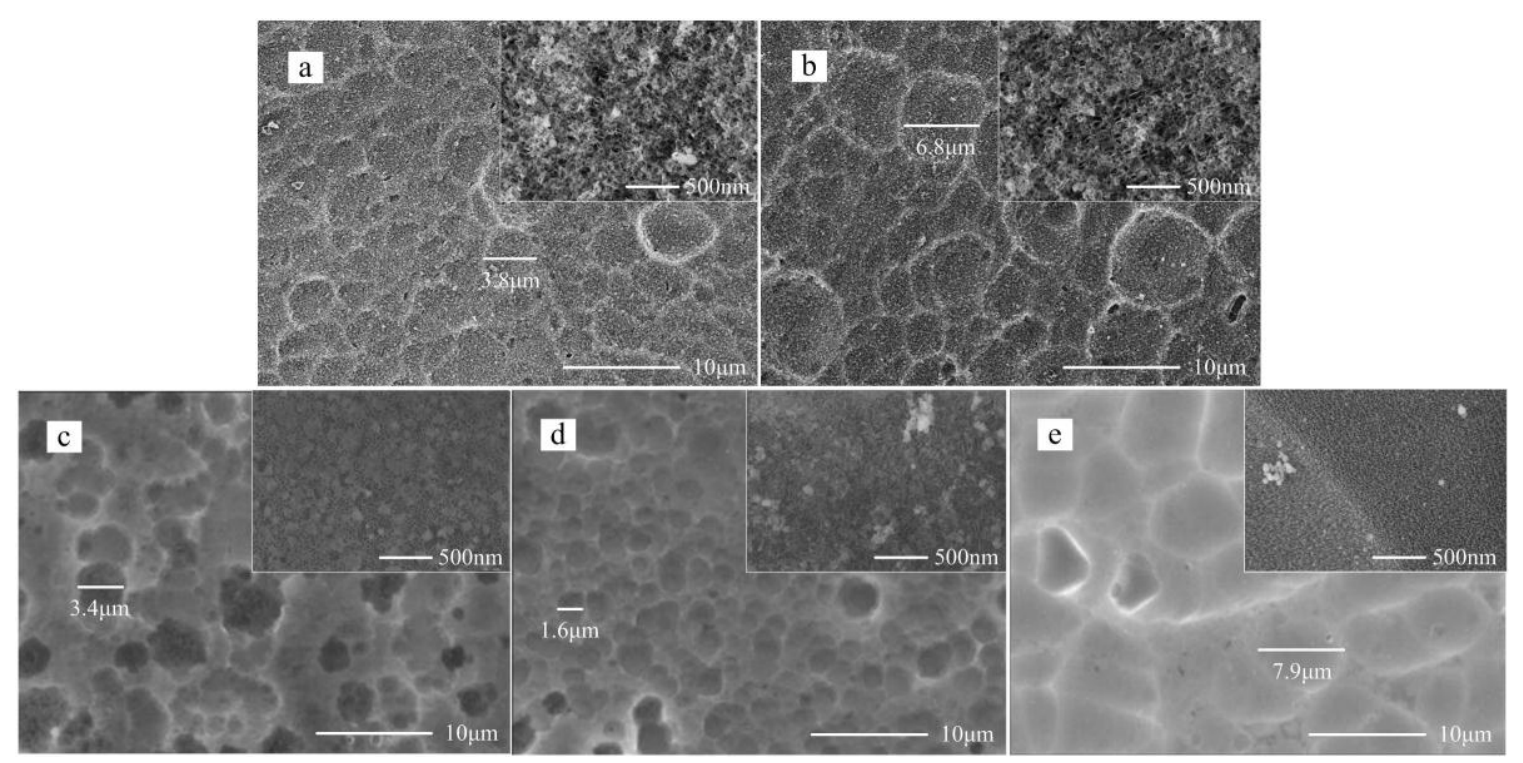

Fig. 4. The surface morphologies of samples with different water contact angles: (a) $6^{\circ}$; (b) $12^{\circ}$; (c) $22^{\circ}$; (d) $35^{\circ}$; (e) $50^{\circ}$.

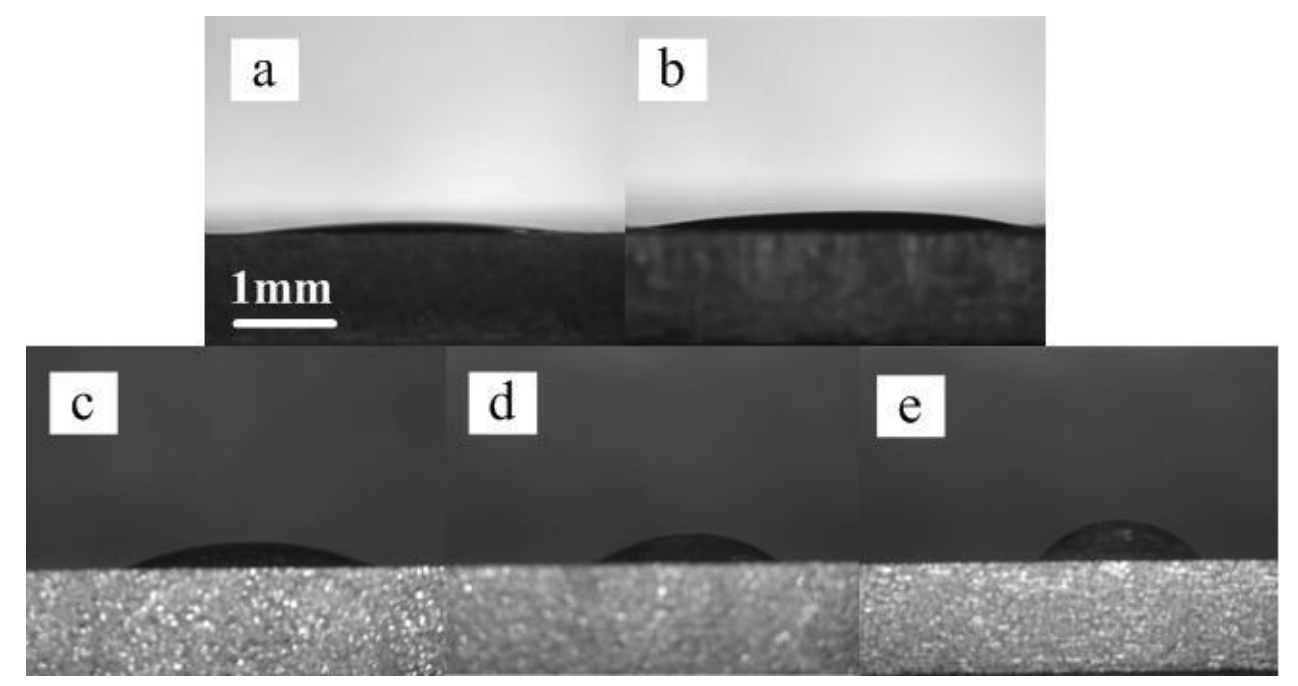

Fig. 5. The contact angle of $4 \mu \mathrm{l}$ water droplets on the anodized aluminum alloy sheets. (a) $6^{\circ}$; (b) $12^{\circ}$; (c) $22^{\circ}$; (d) $35^{\circ}$; (e) $50^{\circ}$

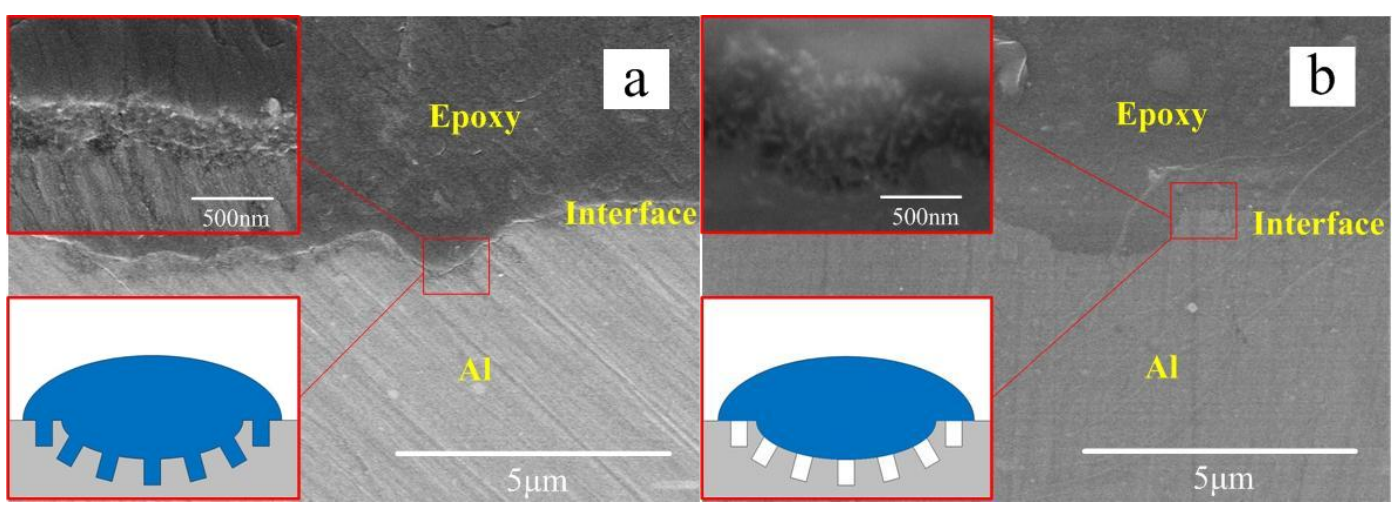

Fig. 6. The mode of epoxy infiltration on porous alumina surface:

(a) mode 1 ; (b) mode 2. 


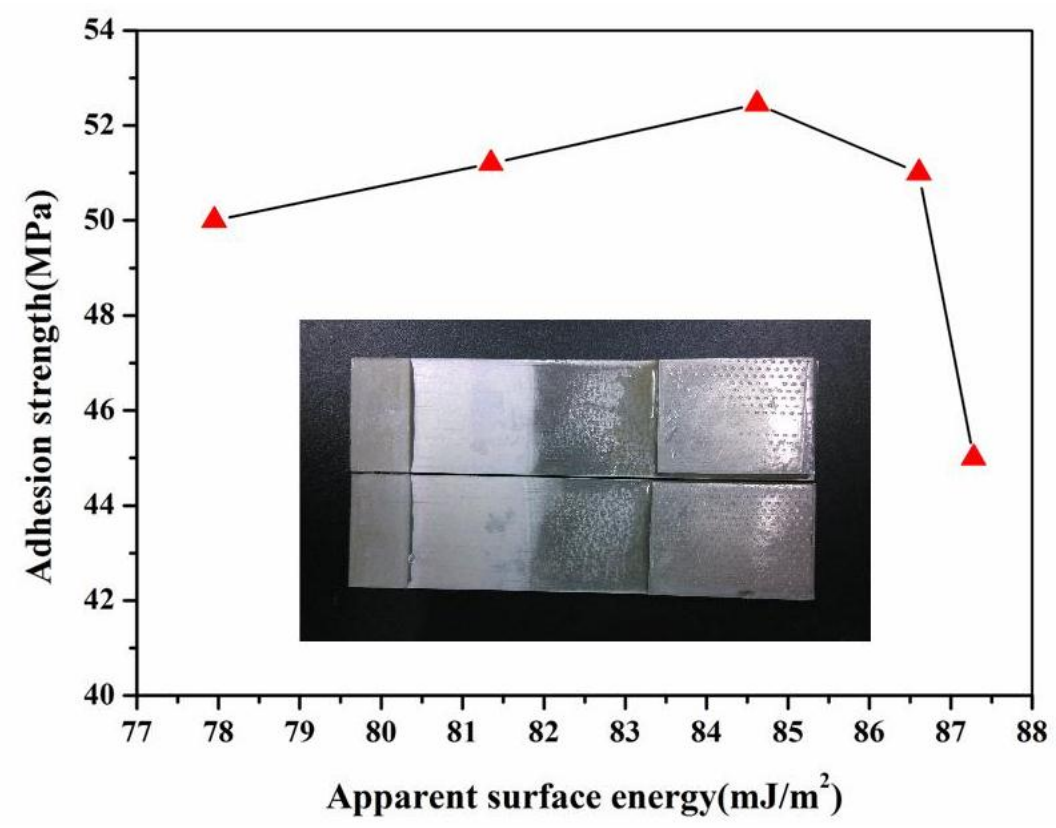

Fig. 7. The adhesion strength of specimens with different apparent surface energy.

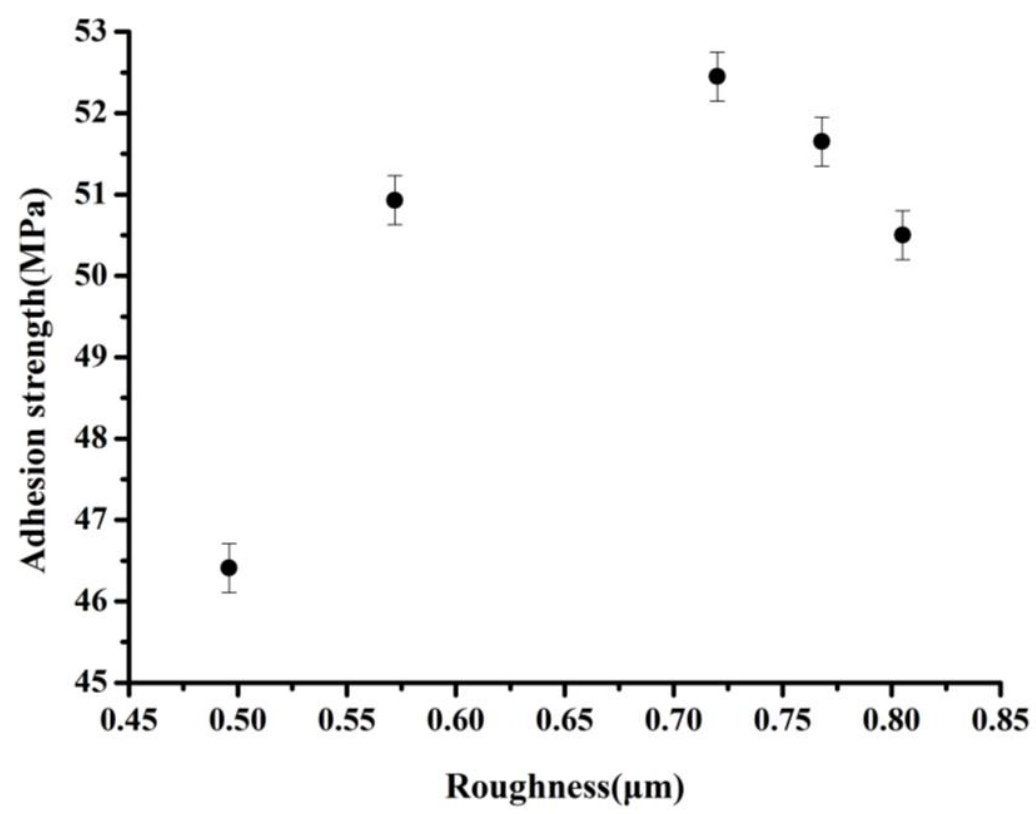

Fig. 8. The adhesion strength of specimens with different roughness values. 


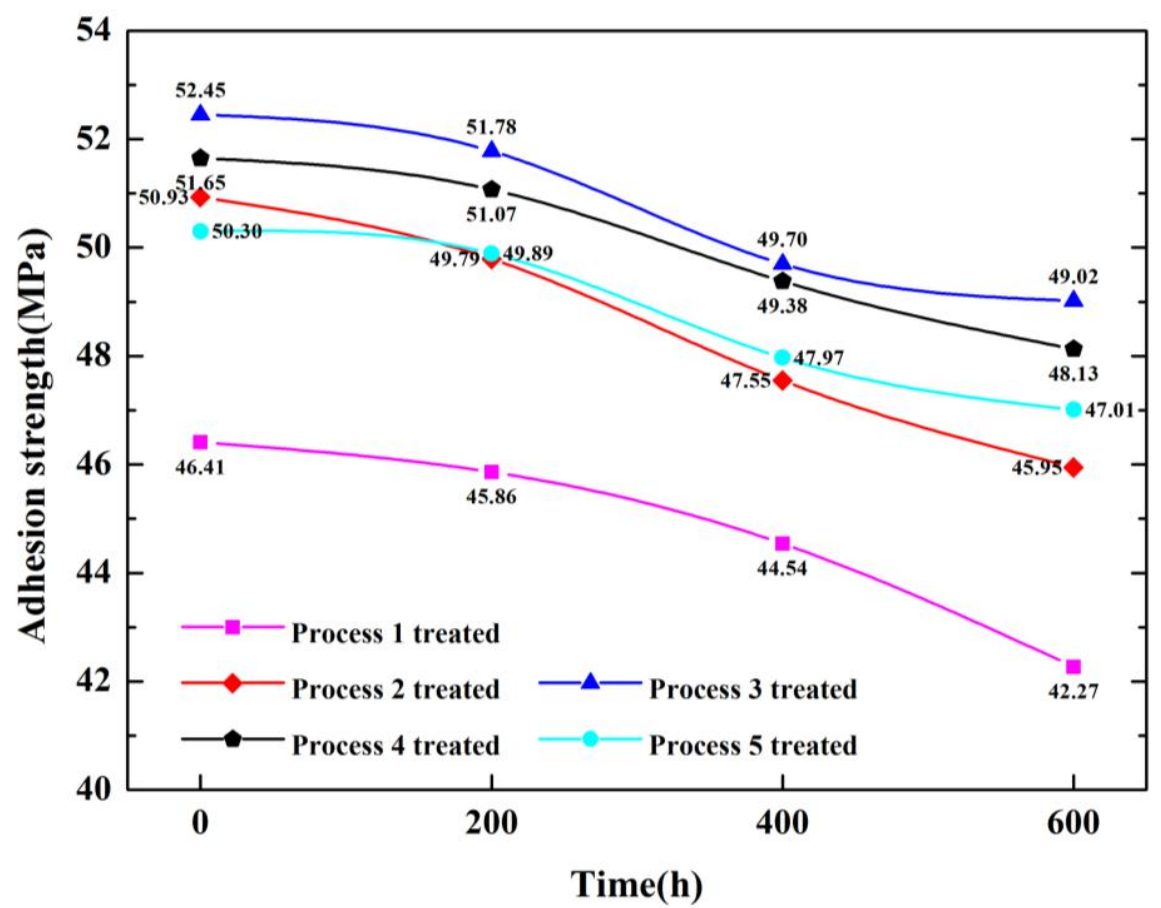

Fig. 9. The durability of aluminum alloy joints bonded with epoxy. 
Tables

Table 1

Experiment parameters of five surface anodizing processes.

\begin{tabular}{ccccc}
\hline Process & Concentration $(\mathrm{g} / \mathrm{l})$ & Temperature $\left({ }^{\circ} \mathrm{C}\right)$ & Voltage $(\mathrm{V})$ & Time $(\mathrm{min})$ \\
\hline 1 & 130 & 20 & 20 & 60 \\
\hline 2 & 150 & 35 & 20 & 30 \\
\hline 3 & 130 & 20 & 10 & 20 \\
\hline 4 & 150 & 20 & 15 & 15 \\
\hline 5 & 100 & 50 & 20 & 30 \\
\hline
\end{tabular}

\section{Table 2}

The value of contact angles, apparent surface energy and roughness of samples.

\begin{tabular}{|c|c|c|c|c|c|c|}
\hline \multirow{2}{*}{ Samples } & \multicolumn{2}{|c|}{ Contact angle $\left({ }^{\circ}\right)$} & \multirow{2}{*}{$\begin{array}{l}\text { Polar component } \\
\qquad\left(\mathrm{mJ} / \mathrm{m}^{2}\right)\end{array}$} & \multirow{2}{*}{$\begin{array}{c}\text { Dispersion } \\
\text { component }\left(\mathrm{mJ} / \mathrm{m}^{2}\right)\end{array}$} & \multirow{2}{*}{$\begin{array}{c}\text { Apparent surface } \\
\text { energy }\left(\mathrm{mJ} / \mathrm{m}^{2}\right)\end{array}$} & \multirow{2}{*}{$\begin{array}{c}\text { Roughness } \\
(\mu \mathrm{m})\end{array}$} \\
\hline & Water & Glycol & & & & \\
\hline 1 & 6.74 & 5.34 & 84.21 & 2.29 & 86.50 & 0.496 \\
\hline 2 & 12.30 & 6.17 & 81.14 & 2.70 & 83.84 & 0.572 \\
\hline 3 & 22.59 & 8.13 & 72.04 & 4.17 & 76.21 & 0.720 \\
\hline 4 & 35.32 & 9.22 & 53.91 & 8.71 & 62.62 & 0.768 \\
\hline 5 & 50.11 & 10.38 & 29.87 & 19.79 & 49.66 & 0.805 \\
\hline
\end{tabular}

\section{Table 3}

Surface tension components of probe liquids

\begin{tabular}{cccc}
\hline Probe liquids & $\begin{array}{c}\text { Polar component } \\
\left(\mathrm{mJ} / \mathrm{m}^{2}\right)\end{array}$ & $\begin{array}{c}\text { Dispersion component } \\
\left(\mathrm{mJ} / \mathrm{m}^{2}\right)\end{array}$ & $\begin{array}{c}\text { Surface energy } \\
\left(\mathrm{mJ} / \mathrm{m}^{2}\right)\end{array}$ \\
\hline Water & 51.0 & 21.8 & 72.8 \\
Glycol & 19.0 & 29.3 & 48.3 \\
\hline
\end{tabular}

